\title{
Head size, brain growth, and lateral ventricles in very low birthweight infants
}

\author{
S W D'SOUZA, M GOWLAND, B RICHARDS, J CADMAN, V MELLOR, D G SIMS, AND \\ M L CHISWICK
}

St Mary's Hospital, Booth Hall Hospital, Manchester and University of Manchester Institute of Science and Technology

SUMMARY Ninety eight newborn infants weighing $<1500 \mathrm{~g}$ at birth and with gestational ages from 26 to 32 weeks were followed prospectively. They were grouped according to real time ultrasound scans in the neonatal period: infants in group $A(n=20)$ had periventricular haemorrhage (PVH) and normal ventricles; infants in group B $(n=26)$ had PVH and dilated ventricles (none with clinical hydrocephalus); and infants in group $\mathrm{C}$, who formed the control group $(n=52)$, had no PVH and normal ventricles. At outpatient follow up a static image ultrasound scanner was used to measure the width of the lateral ventricles and brain hemispheres. The three groups of infants showed similar growth in occipitofrontal circumference, biparietal diameter, and brain hemispheres irrespective of a history of PVH or ventricular dilatation. The relation of ventricle size to biparietal diameter was similar in those infants in groups A (PVH alone) and C (controls) who had a good outcome. About a third $(n=8)$ of the infants in group $B$ had persistent ventricular dilatation in relation to biparietal diameter and a poor outcome associated with developmental delay and cerebral palsy. By contrast, the remaining two thirds $(n=18)$ of the infants in group B who later had smaller ventricles in relation to biparietal diameter showed fewer neurodevelopmental sequelae. It is suggested that persistent ventricular dilatation in relation to biparietal diameter at follow up carries a bad prognosis, which might be due to brain atrophy.

Ultrasound scanning of the neonatal brain is a major advance in the diagnosis of periventricular haemorrhage (PVH). Most studies report such haemorrhages in about $50 \%$ of preterm infants weighing less than $1500 \mathrm{~g}$, and the prevalence of haemorrhage is higher in infants under $1000 \mathrm{~g}$ at birth. ${ }^{1-3}$ Palmer et al have shown that infants with $\mathrm{PVH}$ and ventricular dilatation do not progress as well in their later development as infants with $\mathrm{PVH}$ alone. ${ }^{4}$ Usually, ventricular dilatation occurs in infants who have sustained moderate to severe PVH, but both Palmer et al and Stewart et al have occasionally noted ventricular dilatation occurring after small haemorrhages in the subependymal area and within the ventricles. ${ }^{45}$ Progression to clinical hydrocephalus carries a poor prognosis, due to cerebral palsy, developmental delay, and deficits in hearing and vision in later childhood. ${ }^{5}$ This has raised concern that our usual practice of not intervening in infants with ventricular dilatation until there is rapid head growth and signs of raised intracranial pressure may allow unnecessary neurological damage.

Little is known about the natural history of ventricular dilatation after PVH in infants who do not develop clinical hydrocephalus. We report here our findings on later head growth and growth of the lateral ventricles and of the brain hemispheres in an unselected series of very low birthweight infants.

\section{Patients and methods}

Infants. Ninety eight newborn infants born at St Mary's Hospital between 1980 and 1983 with birth weight $<1500 \mathrm{~g}$ and gestational age 26-32 weeks who survived the neonatal period were followed up prospectively. Their clinical details are shown in Table 1. A real time ultrasound sector scanner fitted with a $5 \mathrm{mHz}$ transducer was used for carrying out neonatal brain scans. ${ }^{67}$ In 20 infants there was haemorrhage in the germinal layer, and in eight of 
Table 1 Clinical details of the 98 infants studied

\begin{tabular}{|c|c|c|c|}
\hline & $\begin{array}{l}\text { Group } A \\
(P V H \text { alone; } \\
n=20)\end{array}$ & $\begin{array}{l}\text { Group } B \\
\text { (PVH and } \\
\text { ventricular dilatation; } \\
n=26)\end{array}$ & $\begin{array}{l}\text { Group C } \\
\text { (normal } \\
\text { controls; } \\
n=52 \text { ) }\end{array}$ \\
\hline \multicolumn{4}{|l|}{ Delivery } \\
\hline Vertex & 10 & 11 & 20 \\
\hline Breech & 1 & 2 & 3 \\
\hline Forceps & 0 & 1 & 1 \\
\hline Caesarean section & 9 & 11 & 28 \\
\hline Face & 0 & 1 & 0 \\
\hline Mean (SD) gestational age (wks) & $29.6(1.9)^{* *} \div$ & $28 \cdot 1(2 \cdot 4)^{* * *}$ & $30 \cdot 8(2 \cdot 1)$ \\
\hline Mean (SD) birth weight (g) & $1139(168)^{*}$ & $1093(202)^{* * *}$ & $1256(179)$ \\
\hline Mcan (SD) occipitofrontal circumference $(\mathrm{cm})$ & $25 \cdot 7(1 \cdot 3)^{*}$ & $26.4(1 \cdot 1)^{* * *}$ & $27 \cdot 1(1 \cdot 5)$ \\
\hline \multicolumn{4}{|l|}{ Neonatal conditions: } \\
\hline Idiopathic respiratory distress & 12 & 14 & 26 \\
\hline Jaundice & 19 & 26 & 49 \\
\hline Septicaemia & 6 & 14 & 9 \\
\hline Patent ductus arteriosus & 6 & 10 & 9 \\
\hline Apnoeic attacks & 4 & 11 & 11 \\
\hline Pneumonia & 8 & 14 & 5 \\
\hline Necrotising enterocolitis & 2 & 7 & 9 \\
\hline Pneumothorax & 4 & 3 & 2 \\
\hline Hypoglycaemia & 2 & 3 & 1 \\
\hline $\begin{array}{l}\text { Congenital anomaly (hydrocele. } \\
\text { dislocated hip. hernia) }\end{array}$ & 2 & 3 & 2 \\
\hline
\end{tabular}

Group A $v$ group C: ${ }^{*} \mathrm{p}<0.05,^{* *} \mathrm{p}<0.01$; Group B $v$ group $\mathrm{C}:{ }^{* * *} \mathrm{p}<0.001$; Group A $v$ group B:† $\mathrm{p}<0.05$.

these infants the haemorrhage extended into the ventricles but without causing obvious dilatation, in that the width of the body of the lateral ventricles was between the $3 \mathrm{rd}$ and 97 th centiles for gestational age. ${ }^{6}$ These formed group A (PVH and normal sized ventricles). In 26 infants the haemorrhage had entered the ventricles and caused dilatation $(>97$ th centile $^{6}$ ), and these formed group B (PVH and dilated ventricles). In three of these infants haemorrhage had extended into the brain parenchyma. The remaining 52 infants had no $\mathrm{PVH}$ and normal sized ventricles ( 3 rd to 97 th centile ${ }^{6}$ ) and formed group $\mathrm{C}$ (controls). The infants were discharged from hospital by their estimated date of delivery ( 40 weeks postconceptional age). Five infants with clinical hydrocephalus (increase in occipitofrontal circumference about $2 \mathrm{~cm} /$ week and crossing centile lines ${ }^{8}$ ) who had received neurosurgical treatment were excluded; otherwise all infants born when ultrasound was available were included.

Follow up. At each clinic visit the occipitofrontal circumference was measured with a paper measuring tape, biparietal diameter with steel callipers, and width of the lateral ventricles and brain hemispheres by static image (grey scale) ultrasound. ${ }^{9}$

Width of the lateral ventricles and brain hemispheres. A static image ultrasound scanner, with a $2.25 \mathrm{mHz}$ transducer, was used. The infant was placed recumbent with his head in the true lateral position. The scanning arm was placed perpendicular to the infant's head, with gel between the transducer probe and the head. Scans were made at $5 \mathrm{~mm}$ intervals from the external auditory meatus to the vertex, parallel to the canthomeatal line. As echoes from the interface between transducer and skin interferred with the quality of images from the same side the dimensions of the lateral ventricle and brain hemisphere were measured on the contralateral side. The infant's head was turned to obtain measurements on the other side. The measurements were made with electronic callipers, at the level of the mid-body of the lateral ventricle, from the midline echo to the first strong echo of the lateral ventricular wall. The hemisphere was measured at the same level from the midline echo to the first strong echo of the inner table of the skull. The standard error of our measurements was $1 \%$ or less. Each infant had between three and five ultrasound scans during follow up in the first year.

Developmental assessment. The Griffiths' scale was used in assessments in the second year, ${ }^{10}$ and a developmental quotient was used to indicate the overall level of development as suggested by Palmer et al. ${ }^{4}$ When abnormal vision or hearing was suspected the infants were referred for specialised ophthalmological and audiometric assessments.

Data analysis. Differences in mean values were compared by Students' $t$ test. Differences in the frequency of proportions between two groups of infants were compared by the $\chi^{2}$ test or Fisher's 
exact test where appropriate. Growth curves were fitted to longitudinal data on the rates of increase in occipitofrontal circumference or biparietal diameter, using an exponential decay model, $y=\mathrm{ae}^{-\mathrm{bx}}$ $+c$. Linear regression analysis $(y=a x+b)$ was used in evaluating the relation of ventricle size to biparietal diameter.

\section{Results}

The clinical details in Table 1 show that infants in groups $\mathrm{A}$ and $\mathrm{B}$ were born earlier than infants in group C. Consequently, infants with PVH (groups A or B) had lower birth weights and smaller occipitofrontal circumference values than those in group $\mathrm{C}$, but the differences were fairly small. Mode of delivery and neonatal complications were similar in the three groups of infants. When the infants were followed up their postnatal age was corrected for prematurity.

Occipitofrontal circumference. biparietal diameter, lateral ventricles, and brain hemispheres in the first year. The data within each subgroup (divided according to estimated date of delivery up to 16 weeks, 17-33 weeks, and 34-50 weeks) in Table 2 are normally distributed, and the timing of measurements were similar in all three groups. The mean occipitofrontal circumference and mean biparietal diameter in the three groups were statistically similar, although infants in group B had larger ventricles. The measurements of left hemisphere and right hemisphere in the three groups were also similar, so it seems that infants in group B with larger ventricles had a narrower width of brain tissue.

Growth rates in occipitofrontal circumference and biparietal diameter. All three groups had similar growth rates in occipitofrontal circumference and biparietal diameter. Thus the growth rates were not significantly affected by PVH or ventricular dilatation. The growth trajectory in each group showed a progressive decline in velocity $(\mathrm{cm} / \mathrm{wk})$ from the estimated date of delivery onwards during the first year (Fig. 1). The period of maximal head growth seemed to extend for a period of about 16 weeks after the estimated date of delivery.

Table 2 Mean (SD) [No of observations] occipitofrontal circumference, biparietal diameter, lateral ventricles, and brain hemispheres $(\mathrm{cm})$ in the first year

\begin{tabular}{|c|c|c|c|}
\hline $\begin{array}{l}\text { Corrected } \\
\text { postnatal age (wks) }\end{array}$ & $\begin{array}{l}\text { Group A } \\
\text { (PVH alone; } \\
n=20)\end{array}$ & $\begin{array}{l}\text { Group B } \\
\text { (PVH and } \\
\text { ventricular } \\
\text { dilatation; } \\
n=26)\end{array}$ & $\begin{array}{l}\text { Group C } \\
\text { (normal } \\
\text { controls; } \\
n=52 \text { ) }\end{array}$ \\
\hline \multicolumn{4}{|c|}{ Occipitofrontal circumference } \\
\hline EDD-16 & $38.26(2 \cdot 56)[30]$ & $37 \cdot 76(2 \cdot 73)[43]$ & $37.68(2.51)[83]$ \\
\hline $17-33$ & $42 \cdot 55(1 \cdot 14)[22]$ & $42 \cdot 19(2 \cdot 36)[27]$ & $42.56(1.59)[61]$ \\
\hline $34-50$ & $44.79(1 \cdot 14)[19]$ & $44 \cdot 31(1 \cdot 83)[25]$ & $44 \cdot 70(1.42)|46|$ \\
\hline \multicolumn{4}{|l|}{ Biparietal diameter } \\
\hline EDD-16 & $9.45(0.76)$ & $9.37(0.77)$ & $9 \cdot 40(0 \cdot 80)$ \\
\hline $17-33$ & $11 \cdot 15(0 \cdot 45)$ & $10.99(0.71)$ & $11 \cdot 19(0.47)$ \\
\hline $34-50$ & $11.74(0.48)$ & $11.44(0.75)$ & $11 \cdot 83(0 \cdot 46)$ \\
\hline \multicolumn{4}{|l|}{ Left ventricle } \\
\hline EDD-16 & $1.44(0 \cdot 13)$ & $1.53(0.18)^{*}$ & $1 \cdot 41(0 \cdot 14)$ \\
\hline $17-33$ & $1.70(0 \cdot 18)$ & $1.69(0 \cdot 14)$ & $1.64(0.15)$ \\
\hline $34-50$ & $1.70(0 \cdot 11)$ & $1.82(0 \cdot 19)$ & $1.71(0 \cdot 13)$ \\
\hline \multicolumn{4}{|l|}{ Right ventricle } \\
\hline EDD-16 & $1.46(0 \cdot 13)$ & $1.54(0.25)^{*}$ & $1 \cdot 40(0 \cdot 15)$ \\
\hline $17-33$ & $1.63(0 \cdot 19)$ & $1.69(0 \cdot 14)$ & $1.63(0 \cdot 14)$ \\
\hline $34-50$ & $1.72(0.12)$ & $1.80(0.23)$ & $1.72(0 \cdot 10)$ \\
\hline \multicolumn{4}{|l|}{ Left hemisphere } \\
\hline EDD-16 & $4 \cdot 28(0 \cdot 34)$ & $4 \cdot 32(0 \cdot 40)$ & $4 \cdot 30(0 \cdot 39)$ \\
\hline $17-33$ & $5 \cdot 16(0 \cdot 36)$ & $5.07(0 \cdot 37)$ & $5 \cdot 14(0 \cdot 30)$ \\
\hline $34-50$ & $5 \cdot 46(0 \cdot 26)$ & $5 \cdot 30(0 \cdot 40)$ & $5.54(0.27)$ \\
\hline \multicolumn{4}{|l|}{ Right hemisphere } \\
\hline EDD-16 & $4 \cdot 25(0 \cdot 33)$ & $4 \cdot 28(0 \cdot 37)$ & $4 \cdot 28(0 \cdot 38)$ \\
\hline $17-33$ & $5 \cdot 11(0 \cdot 30)$ & $5 \cdot 10(0 \cdot 33)$ & $5 \cdot 11(0 \cdot 30)$ \\
\hline $34-50$ & $5.43(0 \cdot 20)$ & $5.34(0.39)$ & $5 \cdot 51(0 \cdot 28)$ \\
\hline
\end{tabular}

EDD $=$ Estimated date of delivery.

${ }^{*}$ Group B $v$ group C, $\mathrm{p}<0 \cdot() \times 1$. 


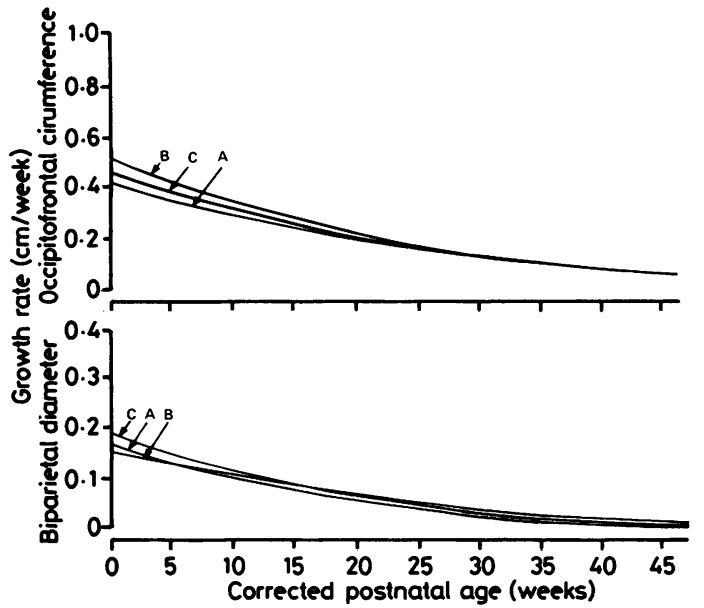

Fig. 1 Growth rate $(\mathrm{cm} / w k)$ in occipitofrontal circumference and biparietal diameter in infants in groups $A, B$, and $C$.

Ventricle size in relation to biparietal diameter. The relation of ventricle size to biparietal diameter was highly significant in infants in group C (190 observations in 52 infants), and this relation was identical for the right and left ventricles (right ventricle $=$ 0.127 biparietal diameter $+0.214, \mathrm{r}=0.98, \mathrm{p}<0.001$; left ventricle $=0.122$ biparietal diameter $+0 \cdot 271$, $r=0.98, p<0.001)$. Infants in groups $A$ and $C$ had a similar ventricle/biparietal diameter relation. Figure 2 shows the regression line and $95 \%$ confidence limits drawn through 190 observations on size of right ventricle in infants in group $\mathrm{C}$. This Figure also shows growth curves of the right and left ventricles in two infants from group $\mathrm{B}$ ( $\mathrm{PVH}+$

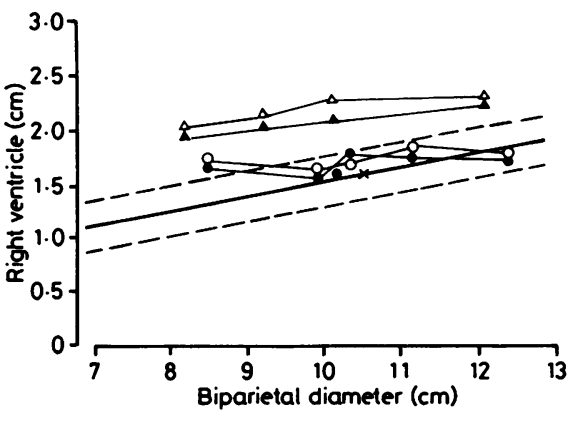

Fig. 2 Width of the right ventricle in relation to the biparietal diameter. The regression line (-) and $95 \%$ confidence limits $(\Xi \Sigma=\Xi=)$ drawn through 190 observations in 52 infants from the control group, group $C$ (see text).

Growth curves for two infants from group $B$ : right $(\triangle)$ and left $(\mathbf{\Delta})$ ventricles in case 1 (persistent ventricular dilatation); right $(\bigcirc)$ and left $(\bigcirc)$ ventricles in case 2 (transient ventricular dilatation).

ventricular dilatation). One growth curve shows persistent ventricular dilatation and the other shows progress to a ventricle/biparietal diameter relation consistent with control values. Of the 26 infants in group B who started off with ventricular dilatation in the neonatal period, 18 showed progress to a ventricle/biparietal diameter relation consistent with controls (transient dilatation), while the remaining eight remained persistently dilated.

In the paragraph above the ventricle size has been related to head growth as measured by the biparietal diameter (Fig. 2). There were eight infants who showed persistent ventricular dilatation. In contrast, if the corresponding Figure is produced using the

Table 3 Outcome in later childhood of the 98 infants studied

\begin{tabular}{|c|c|c|c|c|}
\hline \multirow[t]{2}{*}{ Outcome } & \multirow[t]{2}{*}{$\begin{array}{l}\text { Group A } \\
(P V H \text { alone; } \\
n=20)\end{array}$} & \multicolumn{2}{|l|}{$\begin{array}{l}\text { Group B } \\
\text { (PVH and } \\
\text { ventricular } \\
\text { dilatation; } \\
n=26)\end{array}$} & \multirow[t]{2}{*}{$\begin{array}{l}\text { Group C } \\
\text { (normal } \\
\text { controls; } \\
n=52 \text { ) }\end{array}$} \\
\hline & & $\begin{array}{l}\text { Transient } \\
(n=18)\end{array}$ & $\begin{array}{l}\text { Persistent } \\
(n=8)\end{array}$ & \\
\hline Normal & 19 & 15 & 1 & 50 \\
\hline $\begin{array}{l}\text { Developmental delay (developmental quotient }<80 \text { ) } \\
\text { Neurological abnormality: }\end{array}$ & 1 & 3 & 7 & 2 \\
\hline $\begin{array}{l}\text { Neurological abnormality: } \\
\text { Cerebral diplegia }\end{array}$ & 0 & \multicolumn{3}{|c|}{ Neurological abnormality: } \\
\hline Athetoid & $\begin{array}{l}0 \\
0\end{array}$ & $\begin{array}{l}2 \\
0\end{array}$ & $\begin{array}{l}1 \\
6\end{array}$ & $\begin{array}{l}0 \\
0\end{array}$ \\
\hline Fits & 0 & 2 & 5 & 0 \\
\hline \multicolumn{5}{|l|}{ Partial blindness from } \\
\hline retrolental fibroplasia & 0 & 0 & 2 & 0 \\
\hline Sensorineural deafness & 0 & 0 & 1 & 0 \\
\hline
\end{tabular}

Levels of significance by Fisher's exact test for frequency of developmental delay or neurological abnormality: Group A $v$ group C: not significant; Group B $v$ group C: $\mathrm{p}<0 \cdot 001$; Group A $v$ group $\mathrm{B}: \mathrm{p}<0 \cdot 01$; Group $\mathrm{B}$, transient $v$ persistent: $\mathrm{p}<0 \cdot 02$.

Transient or persistent ventricular dilatation in relation to biparietal diameter.

Normal: developmental quotient $>80$ and no neurological abnormality. 
age after estimated date of delivery' instead of the biparietal diameter on the horizontal axis only six infants are found to have persistent ventricular dilatation (the ventricle size always remaining greater than two standard deviations above the mean for controls). These latter six infants, identified on the age graph, were a subset of the eight infants identified on the biparietal diameter figure.

Outcome in later childhood. Table 3 shows that infants in group A did as well in their development as infants in group $\mathrm{C}$ and had a similar neurological state. Infants in group B had a worse outcome, but much of this could be attributed to a subgroup of eight infants with persistent ventricular dilatation: seven of these infants had developmental delay or a neurological abnormality, which was mostly due to the athetoid type of cerebral palsy. The remaining 18 infants with a later ventricle/biparietal diameter relation consistent with controls generally had a favourable outcome, apart from three infants with developmental delay or cerebral diplegia.

\section{Discussion}

In clinical practice measurements of head size give some indication of brain growth. In our study the initial 16 week period (after the estimated date of delivery) of fairly rapid growth in occipitofrontal circumference and biparietal diameter might be part of catch up growth previously observed in similar preterm infants, after body weight deficits in the neonatal period associated with various illnesses and feeding difficulties. ${ }^{11}$ Indeed, during the catch up period head growth might be preferentially enhanced compared with bodily growth ${ }^{12}$ but should not be mistaken for hydrocephalus. In the present study PVH does not seem to have had a significant effect on subsequent brain growth, judging by measurements of occipitofrontal circumference and biparietal diameter, although the measurements were misleading in eight infants for ventricular dilatation was not reflected in external dimensions of the head. The persistently dilated ventricles in relation to biparietal diameter in these infants possibly indicates brain atrophy.

It is known that the shape of the head alters after birth, since side to side flattening of the skull may take place due to the head lying on one side and then on the other. ${ }^{13}$ As a result there is an apparent change in head configuration from a near circular to an elliptical one, ${ }^{13}$ and we thought that this might influence the dimensions of the ventricles and brain hemispheres. The close correlations between the width of the lateral ventricles and the biparietal diameter suggest that both variables change at a similar rate during growth. This makes it possible to calculate the size of normal ventricles if the biparietal diameter is known, by using our predictive equations. In addition, it should be possible to monitor changes in ventricle size after PVH in relation to biparietal diameter by using Figure 2 .

The static image (grey scale) ultrasound scanner used in this study is an instrument that is commonly used in obstetrics for measurements of fetal biparietal diameter. The accuracy of echo encephalographic measurements of brain ventricles with this technique has been previously established. ${ }^{14} 15$ There is a close correlation between ventricle size measured by static image ultrasound and by computed tomography; also the severity of hydrocephalus indicated by computed tomography is in agreement with that indicated by ultrasound. ${ }^{9}$ A sharp outline of the lateral margin of the ventricles was clearly visible by ultrasound due to differences in acoustic impedance between brain and cerebrospinal fluid. The images seen of the mid-body of the lateral ventricle, a sharp outline of the lateral margin, a midline echo thought to be generated by the septum pellucidum, and a strong echo from the inner surface of the skull, enabled us to carry out accurate measurements. We found it difficult to obtain reproducible measurements with similar accuracy of the transaxial plane with a real time sector scanner.

In relating ultrasound appearances of the brain to later outcome we have shown that the predictive value of neonatal scans can be improved by further ultrasound observations in the first year. When used on an outpatient basis the ultrasound caused little disturbance to the infants, spontaneous activity in infants did not affect the quality of imaging, and sedation was not necessary. Transient ventricular dilatation has previously been reported using real time ultrasound in four $(26 \%)$ of 15 infants with dilated ventricles, after scanning repeatedly for 30 days postnatally, ${ }^{7}$ and eight (38\%) of 21 infants with dilated ventricles who had scans until discharge from hospital. ${ }^{5}$ In both these studies the greater proportion of infants had persistent ventricular dilatation from an assessment based on a fairly short period. In comparison, in our study most dilated ventricles in our infants in group B reverted to normal size after 12 months' observations. On this basis 'transient' ventricular dilatation occurred in $18(70 \%)$ of the 26 infants in group B when the size of the ventricle was assessed in relation to biparietal diameter or in 20 $(77 \%)$ infants when the assessment was according to age after estimated date of delivery. Clearly, it takes a longer time for blood in the ventricles to be absorbed in order that ventricle size can revert to normal.

Early ultrasound findings in our study (Table 2) 
suggest that brain tissue was squeezed by distended ventricles against the inner surface of the skull. Our conclusion comes from the fact that all three groups have the same biparietal diameter, occipitofrontal circumference, and left and right hemispheres, but the ventricle size in group B is clearly increased. Thus if the skull size is fixed the brain must be squeezed when enlarged ventricles are present. This raises a possibility that the immature brain, which is known to contain less myelin, can to some extent accommodate distended ventricles by reducing its relatively large extracellular space. Unfortunately, by relating ventricle size to biparietal diameter in early infancy we cannot be certain whether the brain is merely being squeezed by distended ventricles, with a later possibility of recovery, or whether progressive brain atrophy is taking place. Measurements of head size or rates of head growth are not helpful in distinguishing between the two. Moreover, there is some uncertainty on our part about the reliability of intracranial pressure measurements, using non-invasive techniques, presently available in excluding brain atrophy. As the limitations of these methods in assessing prognosis in early infancy are recognised a more recent approach has been to investigate neonatal brains for periventricular infarction.

Infants with persistent ventricular dilatation may have included those with brain atrophy due to periventricular infarction, which is subsequently associated with retarded development and cerebral palsy. ${ }^{16} 17$ Volpe et al have shown by positron emission tomography that periventricular infarction can be more extensive than the haemorrhage suggests. ${ }^{18}$ Recently, periventricular infarction has been diagnosed by real time ultrasound using a $7 \cdot 5$ $\mathrm{mHz}$ transducer, which provides better resolution. ${ }^{1920}$ Extension of intraventricular haemorrhage into brain tissue carries a higher risk of major disability, and because of this the outlook after intracranial extension has been regarded with considerable pessimism, notably in very premature infants. ${ }^{21}$ The three infants in our study with an intracerebral extension of haemorrhage had, indeed, persistently dilated ventricles and a poor outcome due to developmental delay and cerebral palsy. Thus in assessing outcome after PVH the relation of ventricle size to biparietal diameter at follow up should be used as a prognostic indicator.

The authors thank Professor R D H Boyd for his helpful comments and Miss Janet Crofts and Mrs Elaine Evans for their secretarial help.

\footnotetext{
References

${ }^{1}$ Thorburn RJ, Lipscombe AP, Stewart AL, Reynolds EOR,
}

Hope PL, Pape KE. Predication of death and major handicap in very preterm infants by brain ultrasound. Lancet 1981;ii: 1119-21.

2 Cooke RWI. Factors associated with periventricular haemorrhage $\backslash$ in very low birthweight infants. Arch Dis Child 1982;57:425-31

${ }^{3}$ Levene MI, Fawer C-L, Lamont RF. Risk factors in the development of intraventricular haemorrhage in the preterm neonate. Arch Dis Child 1982;57:410-7.

${ }^{4}$ Palmer P, Dubowitz LMS, Levene MI, Dubowitz V. Developmental and' neurological progress of preterm infants with intraventricular haemorrhage and ventricular dilatation. Arch Dis Child 1982;57:748-52.

5 Stewart AL, Thorburn RJ, Hope PL, Goldsmith M, Lipscombe AP, Reynolds EOR. Ultrasound appearance of the brain in very preterm infants and neurodevelopmental outcome at 18 months of age. Arch Dis Child 1983;58:598-604.

${ }^{6}$ Levene MI. Measurement of the growth of the lateral ventricles in preterm infants with real-time ultrasound. Arch Dis Child 1981;56:900-4.

${ }^{7}$ Levene MI, Starte DR. A longitudinal study of posthaemorrhagic ventricular dilatation in the newborn. Arch Dis Child 1981;56:905-10.

8 Allan WC, Dransfield DA, Tito AM. Ventricular dilatation following periventricular-intraventricular haemorrhage: outcome at age one year. Pediatrics 1984;73:158-62.

9 Johnson ML, Mack LA, Rumack CM, Frost M, Rashbaum C. B-mode echoencephalography in the normal and high risk infant. AJR 1979;133:375-81.

${ }^{10}$ Griffiths R. The abilities of babies: a study of mental measurement. Amersham: Association for Research in Infant and Child Development, 1976.

1 D'Souza SW, Vale J, Sims DG, Chiswick ML. Feeding, growth, and biochemical studies in very low birth weight infants. Arch Dis Child 1985;60:215-8.

12 Fujimura M. Factors which influence the timing of maximum growth rate of the head in low birthweight infants. Arch Dis Child 1977;52:113-7.

13 D'Souza SW, Ross J, Milner RDG. Alterations in head shape of newborn infants after caesarean section of vaginal delivery. Arch Dis Child 1976;51:624-7.

${ }^{14}$ Lombroso CT, Erba G, Yogo T, Logowitz T. Two dimensional ultrasonography: a method to study normal and abnormal ventricles. Pediatrics 1968;42:157-74.

${ }^{15}$ Sjogren I, Bergstrom K, Lodin H. Echoencephalography in infants and children. Acta Radiol [Suppl] (Stockh) 1968;278: 4-83.

16 Anonymous. Ischaemia and haemorrhage in the premature brain [Editorial]. Lancet 1984;ii:847-8.

17 Allan WC, Dransfield DA, Philip AGS. Early treatment for posthaemorrhagic hydrocephalus. Lancet 1983;ii:459-60.

18 Volpe JJ, Herscovitch P, Perlman JM, Raichle ME. Positron emission tomography in the newborn: extensive impairment of regional cerebral blood flow with intraventricular haemorrhage and haemorrhagic intracerebral involvement. Pediatrics 1983; 72:589-601.

19 Levene MI, Wigglesworth JS, Dubowitz V. Haemorrhagic periventricular leukomalacia in the neonate: a real-time ultrasound study. Pediatrics 1983;71:794-7.

20 Dolfin T, Skidmore MB, Fong KW, Hoskins EM, Shennan AT, Hill A. Diagnosis and evolution of periventricular leukomalacia: a study with real-time ultrasound. Early Hum Dev 1984;9:105-9.

21 Cathro-Smith AG, Yu VYH, Bajuk B, Orgill AA, Astbury J. Effect of neonatal periventricular haemorrhage on neurodevelopmental outcome. Arch Dis Child 1985;60:8-11.

Correspondence to Dr S W D'Souza, Department of Child Health, St Mary’s Hospital, Mánchester M13 0JH, England.

Received 4 October 1985 